\title{
Evaluation of Iranian Medical Journals from the Perspective of Publication Ethics
}

\author{
Ehsan Shamsi-Gooshki, MD, PhD ${ }^{1}$; Hasan Bagheri, PhD²; Mahmood Salesi, PhD $^{2 *}$ \\ ${ }^{1}$ Medical Ethics and History of Medicine Research Center, Tehran University of Medical Sciences, Tehran, Iran \\ ${ }^{2}$ Chemical Injuries Research Center, Systems Biology and Poisonings Institute, Baqiyatallah University of Medical Sciences, Tehran, Iran
}

\begin{abstract}
Background: Scientific journals will gain real credit when they meet publication ethics standards. This study seeks to evaluate the current status of medical journals' adherence to some ethical standards.

Methods: The 412 scientific journals approved by the Ministry of Health and Medical Education were included in this study. The process of downloading articles and data extraction for seven general and specific indicators related to publication ethics was conducted by trained researchers. Different methods were implemented by the team of colleagues to prevent possible errors in data extraction. After data integration, data analysis was performed using SPSS version 23.

Results: Overall, 408 journals and 3948 articles met the inclusion criteria. The distribution of journals according to the highest journal index was $5.4 \%, 13.7 \%, 8.3 \%, 8.1 \%$ and $64.5 \%$ for ISI, ESCI, PubMed, Scopus and Other indexes, respectively. In $27.7 \%$ of the articles, the review process took over 6 months. According to the results, $6.6 \%$ and $31.7 \%$ of the articles belonged to the journals' editors and owner universities, respectively. Journal self-citation was seen in $19.2 \%$ of articles and in fewer than half of the articles $(45.5 \%)$, the status of conflict of interest was declared. In $36.9 \%$ of the articles, the code of ethics or university ethics committee approval, and in $36.5 \%$ of clinical trial articles, the clinical trial registration code was reported.

Conclusion: Modifying processes or introducing new rules for indicators of publication ethics by trustee organizations can improve the current status. These seven indicators can also be used to rank journals.

Keywords: Ethics, Indicators, Medical journals, Publications

Cite this article as: Shamsi-Gooshki E, Bagheri H, Salesi M. Evaluation of Iranian medical journals from the perspective of publication ethics. Arch Iran Med. 2020;23(10):697-703. doi: 10.34172/aim.2020.88.
\end{abstract}

Received: January 26, 2020, Accepted: June 29, 2020, ePublished: October 1, 2020

\section{Introduction}

Today, journals represent the achievements of the scientific community, and publishing articles in them is an indicator of the scientific life of that community. ${ }^{1}$ Scientific journals are in fact the means of publishing scientific articles and will find their true credit once the ethical standards are met at all stages of research.

One of the areas related to ethics in research is the observance of ethics in the publication of research papers; this has been one of the most challenging issues in our country in recent years. Adherence to these principles in the field of medical sciences is of paramount importance because research outputs in this field have a significant impact on health planning and treatment processes. $^{2}$

Topics discussed in the field of ethics in the publication of research work may include conflict of interest, plagiarism, fabrication or falsification, copyright and intellectual property, duplicate publication, overlap publication, etc. ${ }^{3-5}$

There have been various discussions and guidelines for publication ethics at international, national, and academic levels. Internationally, there are various guidelines published by trustee organizations, such as the International Committee on Ethics (COPE) or the
International Committee for Medical Journal Editors (ICMJE). At the national level, one of the most important guidelines set out in this regard is the latest amendment to the National Guidelines for Publication Ethics, issued by the Ministry of Health and Medical Education of Iran (MOHME) in March 2018, and the Secretariat of the National Committee for Ethics in Biomedical Research is responsible for monitoring the proper implementation of this guidance.

The latest revision of this guideline covers various chapters titled "Conditions for authorship", "Examples of Research Violations in Reporting and Publishing Scientific Works" and "Ethics principles in Editing and Reviewing Scientific works". ${ }^{6}$ This guideline outlines some of the key principles and standards associated with scientific journals that have not received much attention by researchers and scientific centers and have not yet been properly assessed in medical journals. Therefore, considering the role and importance of scientific journals in the field of science and knowledge, this study aims to assess the current status of medical journals and identify some deficiencies, to give a more objective view of adherence to some ethical standards in the publication of research papers, and finally, provide 
strategic planning to improve the scientific credibility of the country's medical science journals.

\section{Materials and Methods}

The purpose of this study was content analysis of the journals of Iranian medical sciences universities in terms of some general and specific indicators related to ethics in publishing research articles. In this study, we review articles published in scientific journals. Thus, this is a review study. But since we seek to extract some scientometric indicators, it can also be included in the field of scientometrics.

\section{Sampling}

The sample units in this study were articles, and the study population was all published articles in approved medical journals. The sample size required to estimate the proportion of adherence to ethics indicators, as the main goal, was estimated using the formula of proportion estimation. Due to lack of similar comprehensive studies, for an appropriate sample size, this proportion was assumed equal to $50 \%$ for each indicator in the formula. Based on $\alpha=0.05$ and absolute error $=2 \%$, the least sample size was calculated equal to 2401 articles. Based on the number of published articles in one year in Iranian medical journals (approximately 19000 articles) and considering finite population correction, the sample size was decreased to 2133 articles. Sampling was accomplished using stratified sampling. The samples were selected from 412 journals as strata. Sampling within each stratum was achieved using cluster sampling with issues considered as clusters. Due to lack of sufficient information about intra-cluster correlations, the design effect was considered to be 1.5. Thus, the sample size increased to 3200 articles. To supply this sample size, the first issue of the year 2018 was selected as a cluster and all its articles were selected according to the inclusion criteria.

In order to sample the articles, first the list and specifications of the scientific journals approved by the MOHME were extracted from the updated list of these journals, which is available on their website https:// journals.research.ac.ir. This list included 412 approved scientific journals at the time of the survey (November 2018). The full text of the articles was downloaded by two well-trained scholars familiar with article types.

The articles evaluated in this analysis were selected based on the following inclusion and exclusion criteria:

1. Articles related to the active national journals approved by the MOHME were included in this evaluation.

2. Articles published in the first issue of the Persian year 1397 were included for Persian-language journals and the first issue of the year 2018 were included for English-language journals.

3. Articles that were uploaded to the journal site after the download time were not included in this analysis.

4. Letters to editor, editorials, corrections and abstracts were excluded.

5. Journals with more than 50 articles in the issue under review, depending on the type of articles, up to 50 articles were included.

6. Journals whose articles were not accessible in various ways were excluded.

\section{Extraction of Indicators}

In this study, by review of literature on seven general and specific indexes related to publication ethics, three trained doubles-teams extracted the indexes from the downloaded articles and entered them into a researcher-made checklist in Excel format. The seven indexes included length of the article review process, journals' editors share of the articles, journal's owner university share of articles, journal selfcitation, declaring conflict of interest, statement of ethics code and registration code for clinical trial studies.

In addition to the mentioned indicators, some parameters such as journal's writing language, the highest journal index and study type were also evaluated.

To prevent possible errors in recording information, we used the techniques of team leader's continuous communication with the evaluators to correct any problems during the extraction of information, checking $20 \%$ of the information recorded by the doubles-teams by another member, and checking $30 \%$ of the recorded information by the team leader and other contributors.

\section{Statistical Analysis}

After extracting the data and merging them in an Excel file, the data were converted to SPSS version 23 and STATA version 11 . The indicators and variables were described by number, percentage and $95 \%$ confidence intervals. Due to the nature of clustered data, the indicators were compared in various subgroups by clustered chi-square test using the "clchi2" command in STATA with 0.05 as the significance level. The assumption of large expected cell counts underlying chi-square test were confirmed for all of the contingency tables.

\section{Results}

Of the 412 journals that were reviewed, access to articles from 4 journals was not possible due to the lack of full-text articles or uploading corrupt files on the journal site. Thus, 3948 articles from 408 journals met the inclusion criteria and were analyzed. Among these articles, only one article was retracted. The distribution of journals according to the highest index, based on the classification of the National Commission for Medical Journals at Ministry of Health and Medical Education, was 5.4\%, 13.7\%, 8.3\%, 8.1\% and $64.5 \%$ for the ISI, ESCI, PubMed, Scopus and other indexes, respectively. The distribution of articles by the highest journal index was $10.1 \%, 16.9 \%, 9.7 \%, 8.5 \%$ and $54.8 \%$, respectively (Table 1 ).

The results showed that observational studies with 
Table 1. Distribution of Articles and Journals by the Highest Journal Index

\begin{tabular}{lcccc}
\hline \multirow{2}{*}{ Highest Index } & \multicolumn{2}{c}{ Journals } & \multicolumn{2}{c}{ Articles } \\
\cline { 2 - 5 } & $\mathbf{n}$ & $\mathbf{\%}$ & $\mathbf{n}$ & $\%$ \\
\hline ISI & 22 & 5.4 & 397 & 10.1 \\
ESCI & 56 & 13.7 & 667 & 16.9 \\
PubMed & 34 & 8.3 & 384 & 9.7 \\
\hline Scopus & 33 (Persian: 14) & 8.1 & 337 & 8.5 \\
Other & 263 (Persian: 133) & 64.5 & 2163 & 54.8 \\
\hline Total & 408 & 100 & 3948 & 100 \\
\hline
\end{tabular}

ISI, Institute for Scientific Information (Web of Science Journals with impact factor); ESCl, Emerging Sources Citation Index (Web of Science Journals without impact factor).

Table 2. Distribution of Articles by Study Type

\begin{tabular}{lcc}
\hline \multirow{2}{*}{ Type of Study } & \multicolumn{2}{c}{ Articles } \\
\cline { 2 - 3 } & $\mathbf{n}$ & $\%$ \\
\hline Observational & 1714 & 43.4 \\
\hline RCT-human & 675 & 17.1 \\
\hline Experimental animal & 305 & 7.7 \\
\hline Lab & 541 & 13.7 \\
Review & 336 & 8.5 \\
\hline Qualitative & 111 & 2.8 \\
\hline Case report-series & 266 & 6.7 \\
\hline Total & 3948 & 100 \\
\hline
\end{tabular}

RCT, randomized clinical trail.

$43.4 \%$ were the most frequent type of study and qualitative studies with $2.8 \%$ were the least common type of study. Clinical trials and animal studies accounted for $17.1 \%$ and $7.7 \%$ of the articles, respectively (Table 2 ).

The results in terms of some general and specific ethical indexes are reported in Tables 3 to 5 . The results of this study are expressed in terms of each parameter:

\section{Review Process Length (Submission to Acceptance)}

Of all articles, $27.7 \%$ had a review length of over 6 months. This ratio increased in English-language journals with an increase in journal index, ranging from $15.6 \%$ for "other" index to $46.9 \%$ for ISI journals. In Persian-language journals, compared to the journals with "other" index, higher-index journals (Scopus) had a higher proportion of articles with review times more than 6 months. But overall, for similar indexes, Persian-language journals had a higher proportion of articles with review periods of more than 6 months than the English-language journals. The difference in the ratio of articles with a review time of over 6 months was significant across various indexes in English language journals (Tables 3 and 4).

\section{Journals Editors Share of the Articles}

In $6.6 \%$ of articles, the authors were editors who published their articles in their own journal. This ratio in Englishlanguage journals decreased with increasing journal index, from $10.4 \%$ for "Other" indexes to $5.5 \%$ for ISI journals. For Persian-language journals, higher-index journals
(Scopus) had a lower proportion of articles published by editors than the lower-index journals (Other). But overall, for similar indexes, Persian-language journals had a lower proportion of articles published by editors than Englishlanguage journals. The difference in the ratio of articles by the journal's editors in different indexes was significant for English-language journals, but it was not statistically significant for Persian-language journals (Tables 3 and 4).

\section{Journal's Owner University Share of Articles}

In total, $31.7 \%$ of articles were written by authors from the journal's owner university. With the exception of Scopus, this ratio in English-language journals decreased with increasing journal index, from $37.3 \%$ for the "Other" index to $27.8 \%$ for ISI journals. For Persian-language journals, higher-index journals (Scopus) had a higher proportion of university articles than journals with lowerindex journals (Other). But overall, for similar indexes, Persian-language journals with the Scopus index had a higher proportion of the journal's owner university articles than English-language journals, while Persian-language journals with the "Other" index had a lower proportion than English-language journals. The difference in the ratio of the journal's owner university articles was statistically significant between the different indexes in English languages (Tables 3 and 4).

\section{Journal Self-citation Rate}

The journal self-citation rate among the articles was $19.2 \%$. In other words, in almost one fifth of the articles, at least one citation is given to the same journal. This rate in English-language journals increased with increasing journal index, from $10.9 \%$ for "Other" index to $29.5 \%$ for ISI journals. For Persian-language journals, higher-index journals (Scopus) had higher self-citation rates than lowerindex journals (Other). But overall, for similar indexes, Persian-language journals had a higher proportion of selfcitation than English-language journals.

The difference in the ratio of self-cited articles between different indexes in both languages was statistically significant (Tables 3 and 4).

Among the types of studies, the highest proportions of self-citation were $27.0 \%$ and $24.4 \%$ which were related to qualitative articles followed by review articles, while the least pertained to case report studies. The difference in the proportion of self-cited articles between the types of studies was statistically significant (Table 5).

Declaring Conflict of Interest

Only in fewer than half of the articles (45.5\%), the conflict of interest status was clearly declared. This ratio in English-language journals increased as the index of the journal increased, from $59.4 \%$ for the "Other" index to $67.8 \%$ for the ISI journals. But for Persian-language journals, higher-index journals (Scopus) had a lower rate 
Table 3. Determination of Some Publication Ethics Indicators in the Articles

\begin{tabular}{lcc}
\hline Indicators & Articles (\%) & $\mathbf{9 5} \% \mathbf{C l}$ \\
\hline Review process length & & \\
$0-1 \mathrm{~m}$ & 4.5 & $(3.8 \%, 5.2 \%)$ \\
$1-6 \mathrm{~m}$ & 67.8 & $(66.3 \%, 69.3 \%)$ \\
$6-12 \mathrm{~m}$ & 21.1 & $(19.8 \%, 22.4 \%)$ \\
$12-24 \mathrm{~m}$ & 6.2 & $(5.4 \%, 7.0 \%)$ \\
$>24 \mathrm{~m}$ & 0.4 & $(0.2 \%, 0.6 \%)$ \\
\hline Journals' editors share of the articles & 6.6 & $(5.8 \%, 7.4 \%)$ \\
\hline Journal's owner university share of & 31.7 & $(30.2 \%, 33.2 \%)$ \\
articles & 19.2 & $(18.0 \%, 20.4 \%)$ \\
\hline Journal self-citation & 45.5 & $(43.9 \%, 47.1 \%)$ \\
\hline Declaring conflict of interest & & \\
Reporting ethics code & 63.1 & $(61.6 \%, 64.6 \%)$ \\
$\quad$ No & 20.2 & $(18.9 \%, 21.5 \%)$ \\
Yes & 16.7 & $(15.5 \%, 17.9 \%)$ \\
\hline Confirmation & 36.5 & $(32.9 \%, 40.1 \%)$ \\
\hline Reporting RCT registration code
\end{tabular}

of declaring conflict of interest than lower-index journals (Other). Overall, for similar indexes, Persian-language journals had a lower proportion of declaring conflict of interest than English-language journals. The difference in the ratio of articles with clear statement of conflicts of interest among the different indexes in both languages was not significant (Tables 3 and 4).

Among the types of studies, there was no statistically significant difference in terms of the proportion of articles with clear statement of conflicts of interest (Table 5).

\section{Reporting Ethics Code}

Only in $36.9 \%$ of the articles, the code of ethics or ethics committee approval was reported. This ratio in English-language journals increased as the journal index increased, from $35.7 \%$ for the other index to $51.4 \%$ for ISI journals. For Persian-language journals, higher-index journals (Scopus) reported a higher proportion of code of ethics or ethics committee approval than lower-index journals (Other). For similar indexes, a lower proportion of Persian-language articles had code of ethics or ethics committee approval than the English-language articles. The difference in the ratio of articles with ethics code report or ethics committee approval was significant across different indexes in both languages (Tables 3 and 4).

Among the types of studies, the highest rates of reported code of ethics or ethics committee approval were related to clinical trial articles, followed by animal studies $(59.4 \%$ and $54.1 \%$, respectively) and the least to review studies and case report studies. The difference in the proportion of articles with code of ethics or ethics committee approval report was statistically significant among study types (Table 5).

\section{Reporting Clinical Trial Registration Code}

Of all the clinical trial articles (675 articles), only $36.5 \%$ reported clinical trial registration code. This ratio in English-language journals went up with increasing journal index, from $36.0 \%$ for the other index to $64.3 \%$ for ISI journals. For Persian-language journals, higher-index journals (Scopus) had a higher proportion of articles with a clinical trial registration code report than lower-index journals (Other). But overall, for similar indexes, a higher proportion of articles published in Persian-language journals with the Scopus index reported clinical trial codes than English-language journals, while Persian-language articles published in journals with "other" indexes had a lower proportion of clinical trial registration code report compared to English-language journals. The differences in the ratio of articles with clinical trial code report among different indexes in both languages were statistically significant (Tables 3 and 4).

\section{Discussion}

The purpose of this study was to investigate some general and specific indicators of publication ethics in medical journals. Seven indicators were measured in 408 journals

Table 4. Some Publication Ethics Indicators in the Articles by Journal Index and Language

\begin{tabular}{|c|c|c|c|c|c|c|c|c|c|c|}
\hline \multirow{2}{*}{ Language } & \multirow{2}{*}{$\begin{array}{l}\text { Highest } \\
\text { Index }\end{array}$} & \multirow{2}{*}{$\begin{array}{c}\text { Review Time } \\
>6 \mathrm{~m}\end{array}$} & \multirow{2}{*}{$\begin{array}{l}\text { Journals Editors } \\
\text { Share of the } \\
\text { Articles }\end{array}$} & \multirow{2}{*}{$\begin{array}{c}\text { Journal's Owner } \\
\text { University Share } \\
\text { of Articles }\end{array}$} & \multirow{2}{*}{$\begin{array}{c}\text { Journal Self- } \\
\text { citation }\end{array}$} & \multirow{2}{*}{$\begin{array}{l}\text { Declaring } \\
\text { Conflict of } \\
\text { Interest }\end{array}$} & \multicolumn{3}{|c|}{ Ethics Code } & \multirow{2}{*}{$\begin{array}{c}\text { RCT } \\
\text { Registration } \\
\text { Code }\end{array}$} \\
\hline & & & & & & & No & Yes & Confirmation & \\
\hline \multirow{6}{*}{ English } & ISI & $46.9 \%$ & $5.5 \%$ & $27.8 \%$ & $29.5 \%$ & $67.8 \%$ & $48.6 \%$ & $23.7 \%$ & $27.7 \%$ & $64.3 \%$ \\
\hline & $\mathrm{ESCl}$ & $34.1 \%$ & $6.7 \%$ & $26.2 \%$ & $23.1 \%$ & $65.8 \%$ & $54.1 \%$ & $20.7 \%$ & $25.1 \%$ & $64.0 \%$ \\
\hline & PubMed & $36.2 \%$ & $6.0 \%$ & $36.5 \%$ & $25.0 \%$ & $56.8 \%$ & $55.7 \%$ & $20.1 \%$ & $24.2 \%$ & $53.8 \%$ \\
\hline & Scopus & $22.8 \%$ & $7.0 \%$ & $30.5 \%$ & $13.4 \%$ & $58.1 \%$ & $56.4 \%$ & $24.4 \%$ & $19.2 \%$ & $40.7 \%$ \\
\hline & Other & $15.6 \%$ & $10.4 \%$ & $37.3 \%$ & $10.9 \%$ & $59.4 \%$ & $64.3 \%$ & $18.2 \%$ & $17.5 \%$ & $36.0 \%$ \\
\hline & $P$ value & $<0.001$ & 0.050 & 0.004 & $<0.001$ & 0.806 & \multicolumn{3}{|c|}{0.039} & 0.031 \\
\hline \multirow{3}{*}{ Persian } & Scopus & $30.9 \%$ & $1.8 \%$ & $37.2 \%$ & $30.9 \%$ & $9.1 \%$ & $61.2 \%$ & $32.1 \%$ & $6.7 \%$ & $51.6 \%$ \\
\hline & Other & $24.5 \%$ & $4.5 \%$ & $28.8 \%$ & $16.3 \%$ & $16.6 \%$ & $74.8 \%$ & $18.4 \%$ & $6.8 \%$ & $19.9 \%$ \\
\hline & $P$ value & 0.374 & 0.192 & 0.157 & 0.014 & 0.385 & \multicolumn{3}{|c|}{0.022} & 0.002 \\
\hline
\end{tabular}

RCT, Randomized Clinical Trail; ISI, Institute for Scientific Information (Web of Science Journals with impact factor); ESCI, Emerging Sources Citation Index (Web of Science Journals without impact factor). 
Table 5. Some Publication Ethics Indicators in the Articles by Study Type

\begin{tabular}{|c|c|c|c|c|c|}
\hline \multirow{2}{*}{ Study Type } & \multicolumn{3}{|c|}{ Ethics Code } & \multirow{2}{*}{ Self-Citation Journal } & \multirow{2}{*}{$\begin{array}{c}\text { Declaring Conflict of } \\
\text { Interest }\end{array}$} \\
\hline & No & Yes & Confirmation & & \\
\hline Observational & $57.6 \%$ & $21.9 \%$ & $20.5 \%$ & $18.6 \%$ & $44.9 \%$ \\
\hline RCT-human & $40.7 \%$ & $37.4 \%$ & $22.0 \%$ & $19.0 \%$ & $47.2 \%$ \\
\hline Experimental animal & $45.9 \%$ & $25.9 \%$ & $28.2 \%$ & $17.4 \%$ & $48.5 \%$ \\
\hline Lab & $84.5 \%$ & $7.2 \%$ & $8.3 \%$ & $22.4 \%$ & $44.0 \%$ \\
\hline Review & $94.9 \%$ & $3.9 \%$ & $1.2 \%$ & $24.4 \%$ & $43.8 \%$ \\
\hline Qualitative & $53.2 \%$ & $31.5 \%$ & $15.3 \%$ & $27.0 \%$ & $42.3 \%$ \\
\hline Case report-series & $94.7 \%$ & $1.5 \%$ & $3.8 \%$ & $9.0 \%$ & $47.7 \%$ \\
\hline$P$ value & \multicolumn{3}{|c|}{$<0.001$} & $<0.001$ & 0.980 \\
\hline
\end{tabular}

$\mathrm{RCT}$, randomized clinical trial.

approved by the MOHME.

\section{Review Process Length}

The results of this study showed that on average; nearly $28 \%$ of Iranian journals had a review process length of above 6 months. This prolonged review process for higherindex journals is inappropriate and even includes about half of ISI journals. However, in accordance with section 3-15 of the National Guidelines for Publication Ethics, reviewers must complete the review process within the deadline announced by the editor-in-chief. ${ }^{6}$

Various factors, such as lack of specification of a review deadline to reviewers, the voluntary nature of reviewing, and the prolongation of the authors' revisions, may lead to the prolongation of the review process. Therefore, for a more detailed evaluation of the review time, it might be advisable to allow two time intervals, the time of submission until reviewer's initial response and the time of submission of the revised manuscript until acceptance, so that the length of time the paper is revised by authors can be deduced from the entire review process. But due to lack of access to these times in national journals, this evaluation was not possible. Prolongation of the review period has become one of the major challenges in publishing articles.

The reasonable review process length for journals has become an important question. Although the length of the review process varies between different journals and depends on the size, scope, the type of article, and the peer review process, the results of this study showed that for a significant proportion of articles, the duration of review process went well beyond what is acceptable. A practical suggestion in this regard seems to be to set reasonable timescales for various journals by a specialized workgroup, and to consider the journals' compliance with this timeframe in ratings.

Journals Editors and Journal's Owner University Share of Articles

According to the results of this study, shares of editors and journal's owner university of articles were $6.6 \%$ and $31.7 \%$, respectively. In terms of journal index, Persian
Scopus journals were in the best position with respect to the share of editors, but were not good regarding the university share.

Perhaps the closest study is one conducted by Rahimi et al from the scientometric group of Shiraz University and its results were published in an article entitled "the ethical approach of editors and their share in publishing in their own journal". In this study, the articles published in 2011 and 2012 in 248 Persian-language journals approved by the Ministry of Science and Technology from eight different scientific fields were investigated. This list included 38 journals with 4379 medical sciences articles. They showed that editors had the highest share of journals in the three fields of Natural Resources, Humanities and Agriculture and the lowest share of editors was observed in medical $(2 \%)$ and veterinary journals.

On the other hand, although medical journals have the lowest share of editors compared to other subject areas, they have the highest share (43\%) of articles published by authors affiliated with the same university. ${ }^{7}$ Comparison of these results with the present study shows that for the Persian-language journals during the years 2012 to 2018, the share of the journal's owner university was slightly reduced, while the share of journal editors was slightly increased.

In the "guideline for the validation of the scientific journals of the country", approved by the Ministry of Science and Technology in February 2011, the share of editors and university were set a maximum of $40 \%$ and $50 \%$, respectively. But a revision in 2019 set the university's share of the journal's articles at a maximum of $30 \%$ for each issue and the share of the editors' group was changed to two articles per member in a year. ${ }^{8}$

However, given the nature of the medical journals in this study and in accordance with the MOHME's guidelines for compliance with section 3-21 of the National Guidelines for Publication Ethics, journal editors and officials are allowed up to $20 \%$ authorship in their journal articles. ${ }^{6}$ Although this cutoff also includes editorial board members who have not been investigated in our research, it still seems that the contribution of the journal's editors 
is acceptable. It may even be possible to reduce the level of this cutoff point for those in charge to below $20 \%$.

Concerning the Journal's owner university in university journals, section 3-17 of the National Guidelines for Publication Ethics introduces the notion of editorial independence, in the sense that editors are not under pressure from journal owners, but it does not specify a specific amount for the journals' owner. ${ }^{6}$ Therefore, considering the importance of universities and their leveraging, setting a cutoff point for the number of articles from the journals' owner university by a specialized workgroup and considering journals' compliance with this principle in ranking journals seems necessary.

\section{Journal Self-citation}

A Journal self-citation is a citation to an article published in the same journal. ${ }^{9}$ We found that in at least one-fifth of the articles, at least one citation was made to the same journal where the article was published. The proportion of self-cited journal articles for journals with higher indexes was inappropriate, accounting for nearly $30 \%$ of the articles indexed in ISI and Persian Scopus journals.

Impact Factor and citation counts are considered as the scientific quality criteria of journals. Editors generally tend to increase the number of journal citations by publishing quality articles. But this technique does not always lead to the expected increase in the number of citations. Editors may be pressured by the publisher because of financial problems or gaining academic credentials. One of editors' selective ways to increase citations is to enhance journal self-citation. In some cases, editors ask authors to cite recent journal articles. ${ }^{10}$ However, high self-citation is not necessarily provoked by editors-in-chief and part of this self-citation may be due to the specialized nature of some journals. ${ }^{11}$ But according to the results of this study, this amount of self-citation makes at least some sense that some editors may encourage authors to cite journal articles or editorial articles in that journal.

In accordance with section 3-23 of the National Guidelines for Publication Ethics, editors cannot pressure authors to cite articles in previous issues of the journal. ${ }^{6}$ This section actually prohibits the journal from offering or coercing self-citation but still does not specify the proportion to which the journal can normally be cited by a researcher. Therefore, given the direct impact of selfcitation on increasing the credibility of journals in the form of indexes such as impact factor, a practical suggestion is to determine a suitable cutoff point for the amount of selfcitation in journals by a specialized workgroup. This cutoff can be considered in the ranking of journals.

\section{Declaring Conflicts of Interest}

Conflicts of interest can occur for different economic and non-economic reasons and at the levels of editors-inchief, reviewers or authors. At the author's level, economic reasons are the most obvious source of conflict that can exist at any stage of a research and cause error in the conclusions of the research. Clarification of conflicts of interest by authors is the simplest and most important step towards building trust in research communications. ${ }^{12}$

This study also examined the authors' conflicts of interest status and found that fewer than half of the articles (45.5\%) declared the authors' conflicts of interest. This ratio is more favorable in English journals, and in nearly two-thirds of ISI journals, there is a clear statement of conflicts of interest. The worst situation in this regard was noted in Persian Scopus journals whose transparency was well below the average of Iranian journals.

Although conflicts of interest re more important for clinical trial studies and authors and journals in these studies have to pay serious attention to this topic, the results of this study showed no significant difference between types of studies in declaring conflicts of interest. Sections 2-7 and 2-8 of the National Guidelines for Publication Ethics emphasize the declaration of conflicts of interest. ${ }^{6}$ These legal requirements block the way to conceal the topic of conflicts of interest and policy makers and journal editors can ensure declaring conflicts of interest during submission of an article or in the process of reviewing.

\section{Report of Ethics and Clinical Trial Registration Code}

On average, $36.9 \%$ of articles have a code of ethics or university ethics committee approval, and in 36.5\% of clinical trials, the clinical trial registration code was reported. This was more favorable in the higher-index journals, and in ISI journals, in which the code of ethics was reported in half of the articles, and the clinical trial registration code was mentioned in two-thirds of the clinical trial articles.

In a similar study, Nojomi et al reviewed a sample of clinical trial articles from 80 Iranian journals indexed between 2008 and 2010 at Iran Medex. They showed that only $12.4 \%$ of them reported the registration code. ${ }^{13}$ A comparison with the results of this study shows that attention to clinical trial registration code has improved over the years. Similar studies have reported varying levels of reporting of the code of ethics in Iran and other countries: the code of ethics or ethics committee approval was reported in $43.5 \%$ of Iranian nursing journal articles in $2014,{ }^{14} 53 \%$ of Argentinian cardiovascular interventional studies in $2008,{ }^{15} 24.2 \%$ of Indian journal articles in $2014,{ }^{16}$ and $51.1 \%$ of European otolaryngology articles in $2015 .^{17}$

In Iran, the code of ethics was mandated for all research projects in 2016 and, according to section 3-3 of the National Guidelines for Publication Ethics, authors and journals were required to mention both codes in articles. ${ }^{6}$ However, the results of this study revealed that the importance of reporting these codes in articles is not yet well understood. Thus, similar to conflicts of interest, it 
seems that policymaking to increase code reporting seems necessary.

\section{Study Limitations and How to Reduce Them}

Due to some technical flaws in the journals' websites, the full text of some articles could not be accessed, or due to vague affiliations in articles, extraction of some parameters was hampered. These problems were partially resolved by various techniques, such as accessing the print version of the journal or referring to various databases.

In conclusion, the results of this evaluation delineated a realistic perspective of the Iranian medical science journals and showed that medical journals were at a moderate level in terms of some of the studied indicators. For some of the indicators such as reporting the code of ethics, reporting clinical trial code, declaring conflicts of interest, etc, for which legal requirements are developed by trustee organizations, modification of the processes can lead to the enforcement of these rules and improvement of the current status.

However, some indicators such as the length of review process, journal's owner university share of articles and the rate of journal self-citation have not been defined objectively in an acceptable and tangible manner. Thus, it is necessary for specialized workgroups of trustee organizations to specify the limits and incorporate them into the existing rules.

Because these seven indicators are measurable for journals, they can be used, individually or in combination, to rank journals, and the improvement of journals in terms of these indicators can be evaluated in longitudinal studies and at specific time intervals.

\section{Authors' Contribution}

ES, HB and MS: Study concept and design, interpretation of data, critical review, approving and revising of the final manuscript. MS: Data gathering and statistical analysis. ES and MS: Drafting of the initial manuscript.

\section{Conflict of Interest Disclosures}

While conducting the research, the first author of the paper (Ehsan Shamsi Gooshki) was the Secretary of the National Committee for Ethics in Biomedical Research and the principal contributor to the development of the new version of the National Guidelines for Publication Ethics. The other authors declare that they had no conflicts of interest in this study.

\section{Ethical Statement}

The study was approved by the Ethics Committee of Shahid Rajaie Cardiovascular Medical and Research Center (Approval code: IR.RHC.REC.1397.061). According to the principles of confidentiality and, the results could only be published with the permission of the Iran National Committee for Ethics in Biomedical Research.

\section{Funding}

This article is the result of a research project conducted at the Shahid Rajaie Cardiovascular Medical and Research Center with the support of the Iran National Committee for Ethics in Biomedical Research in 2018.

\section{References}

7. Mohseni M. Investigating the external and internal problems of scientific journals in Iran. Journal of Academic Librarianship and Information Research. 2002;36(39):41-71.

8. Smith R. The trouble with medical journals. J R Soc Med. 2006;99(3):115-9. doi:10.1258/jrsm.99.3.115.

9. Rezaeian M. Conflicts of Interest. JRUMS. 2009;8(3):157-8. [in Persian].

10. Martyn C. Fabrication, falsification and plagiarism. QJM. 2003;96(4):243-4. doi:10.1093/qjmed/hcg036.

11. Smith ER. Plagiarism, self-plagiarism and duplicate publication. Can J Cardiol. 2007;23(2):146-7. doi:10.1016/ S0828-282X(07)70736-5.

12. The National guideline of ethics in publishing research works. 2018. Available from: http://ethics.research.ac.ir/docs/ publication_guideline.pdf? cbt=2. Accessed 2018. [Persian].

13. F. Rahimi , F. Alinezhad, M. Kohandel, S. Mirhaghjoo. Ethical Approach of Editors-in-Chief and Their Share of Publishing Articles in Their Own Journals. Journal of Ethics in Science and Technology. 2016;11(1):51-61.

14. Ministry of Science, Research and Technology of the Islamic Republic of Iran. Regulations of scientific journals approved in Ordibehesht 1398 (May 2019). Available from: https:// rppc.msrt.ir/file/download/download/1556595627-1398.pdf. [Persian].

15. Egghe L, Rousseau R. Introduction to informetrics: Quantitative methods in library, documentation and information science. Elsevier Science Publishers; 1990.

16. Krauss J. Journal self-citation rates in ecological sciences. Scientometrics. 2007;73(1):79-89. doi:10.1007/s11192-0071727-7.

17. Rousseau R. Temporal differences in self-citation rates of scientific journals. Scientometrics. 1999;44(3):521-31. doi: 10.1007/bf02458493.

18. Gasparyan AY, Ayvazyan L, Akazhanov NA, Kitas GD. Conflicts of interest in biomedical publications: considerations for authors, peer reviewers, and editors. Croat Med J. 2013;54(6):600-8. doi:10.3325/cmj.2013.54.600.

19. Nojomi M, Ramezani M, Ghafari Anvar A. Quality of reports on randomized controlled trials published in Iranian journals: application of the new version of consolidated standards of reporting trials (CONSORT). Arch Iran Med. 2013;16(1):20-2.

20. Heydari A, Pourghaznein T. Critical Appraisal of the Ethical Considerations' Reports in Nursing Studies Published by Iranian Nursing Journals. IJN. 2015;28(93):66-77. doi: 10.29252/ijn.28.93.94.66. [Persian].

21. Borracci RA, Calderón G, Seoane MR, Perez AC, Doval HC. Ethical review and informed consent in cardiovascular research reports in Argentina. Arq Bras Cardiol. 2008;90(5):317-21. doi:10.1590/s0066-782×2008000500002.

22. Belhekar MN, Bhalerao SS, Munshi RP. Ethics reporting practices in clinical research publications: A review of four Indian journals. Perspect Clin Res. 2014;5(3):129-33. doi:10.4103/2229-3485.134316.

23. Murphy S, Nolan C, O'Rourke C, Fenton J. The reporting of research ethics committee approval and informed consent in otolaryngology journals. Clin Otolaryngol. 2015;40(1):36-40. doi:10.1111/coa.12320. 